\title{
Human Genome Mapping: A Step Forward in Understanding the Languages of Heredity
}

\author{
Md. Abdus Salam
}

Just imagine the situation when a prospective candidate looking for a job needs obligatory to provide his or her personal genetic map along with other documents to the potential employers or if it is mandatory for a prospective groom to show his genetic map for marriage! It sounds more a science fiction than reality but is going to be applicable soon with the great news of completion of human genome mapping. Know thyself of Socrates will be revealed through genetic codes.

\section{The great news for mankind}

Just over a decade back, the ever so challenging task to map and navigate human genes was started in the name of Human Genome Project (HGP). Since then dozens of molecular biologists of 18 different countries including USA, UK and Japan took part in this huge task simultaneously using a good number of super computers ${ }^{1,2}$. Scientists initially fixed up their target to accomplish the task by 2005 . Selera Genomix, a non-government agency in the US also started the same task and it was Craig Venter of Selera Genomix, an American scientist who declared that they would be able to complete the gene mapping before HGP. Due to a real healthy competition among the scientists, the goal has been achieved five years earlier than the speculated time.

26 June 2000 is a historical landmark for the mankind when the great news of accomplishment of genome mapping came out as a joint declaration fruer both HGP and Selera Genomix. The HGP has claimed that they have identified at least $97 \%$ of the gesome while the Selera Genomix has clained it e fe $99 \%$. Now it is a matter of only a year or two when the remaining task will be accorplistof?"

\section{What is genome and genome mapping?}

Before going to answer this question let us have a very simplified idea regarding basic human gene architecture. Chromosomes in a somatic cell contain innumerable genes, the unit of heredity. Although the exact number of gene is yet to be established but it is estimated to be around 100000. Besides transmission of hereditary characteristics, these genes also direct the production of proteins, which are invaluable for bodybuilding.

Four different nucleotides namely Adenine (A), Thymine (T), Guanine (G) and Cytosine (C) are the chemical basis of inheritance that forms the DNA. In its conformational structure, DNA is a double helix, which can be compared with a twisted staircase where each step contains two nucleotides in a pair called base pair. The pairing occurs between A \& T and G \& C widely known as Watson Crick base pairing. A single somatic cell contains about 3000 millions ATGCs. So to mean human genome, it accounts all chromosomes, DNA, genes and these ATGCs present in all 10 trillions human cells ${ }^{4}$. Mapping is the construction of a series of chromosome descriptions that depict the position and spacing of unique, identifiable biochemical landmarls including some genes that occur on the DNA of chromosomes.

\section{Why this gene mapping?}

No two human beings is alike at their DNA configuration although there is very minima difference. It is said that there is 99.999 simelariy between two persons in their DNA sequence) but 
due to this $0.01 \%$ dissimilarity, two persons are seally two different individuals. In the language of penetics, if we consider the human genome as a book then it is written by using four different letters called ATGC. Differences between two persons are again because of differences in the arrangement in their ATGCs. On an average, 0.3 millions letters are different from one individual to another. For example, a person may hatve arrangements like ATCGTCAGCTA whereas another person may have ATCGTGAGCTA. This change in $\mathrm{C}$ to $\mathrm{G}$ only will probably make Rahim to Rahman.

Roughly an average size gene contains 1500 nucleotides of ATGCs and a special arrangement of three bases together constitutes a genetic code or codon. Out of total 64 codons, 61 are engaged to specify 20 different amino acids to form polypeptide chains and the remaining 3 mark the beginning and ending of protein synthesis. Thus revealing genetic codes means understanding the mystery of protein production and in this way scientists are rationally optimistic that one day they will be able to explore the mystery of life in this universe when genetic codes of all proteins will be revealed.

\section{What implications the genome mapping will have?}

Considering its good and bad implications there is a big hue and cry with the breaking news of human gene map. Scientists are naturally proud for this noble achievement and claiming it as some thing more successful event than to reach the moon. Many would like to claim it as the greatest achievement for mankind ever, because human gene map will be able to bring unimaginable benefits. The most important target of utilizing the knowledge of human gene map is in the field of medicine. As days are going by it is being revealed increasingly that most diseases have some sort of gene related etiology. Now with the advent of the knowledge of gene locus and its sequences it will be easier to check any fault within the gene in the genesis of any disease and accordingly therapy will be devised, Gene therapy. the most appropriate form of treatment for genetic diseases will be possible. So in that context, the gene map will make revolution especially in the field of medicine and bio-pharmaceuticals.

Now what is there on the other side of the coin? It is not very difficult to imagine the ill effects of this knowledge acquired through gene mapping. There will be nothing called secrete in a person with the availability of genetic database. Simply by seeing the genetic profile of a person it will be easier to say whether the person is innocent or criminal, honest or dishonest, has been suffering from any genetic disease or will be suffering from any disease in near future etc. More over the possibility of abuse of genetic codes can make this earth simply hail. There will be a big chaos in the job market when employers will ask for genetic profile of the candidates seeking employment. Like wise, many more threats lie in the unethical use and mishandling of genetic codes by over ambitious muscreants. Finally gene therapy involving germ line genes is a real ethical controversial issue. Because, it is argued that one does not have the right to impose such a change to the descendants what so ever well intentions are reasoned ${ }^{6}$.

\section{References}

1. Baxevainis A D. The Molecular Blology Database Collection: 2003 Update. Nucleic Acid Res. 2003. 31:1-12

2. Cuticchia A J High Performance Computing And Medical Research. Can Med Assoc J. 2000; 162 . 1148-49.

3. Collins F. Patrinos A et al. New Goals for the U.S Human Genome Project: 1998-2003. Science 1998: 182: $682-689$

4. Venter J C, Adams M D, Myers E W ot al. The Sequence of the Human Genome, Science 2001. 291-1304-1351.

5. Collins $F, S$, Mckusick $\vee$ A. implications of the Human Genome Project for Medical Science. JAMA 2001; 285:540-44.

6. Collins F S. Medical and Societal Consequences of the Human Genome Project. N Engl J Med 1999: 231: $28-37$.

All comespondence to

Dr. Md. Abdus Salam Assistant Protessor

Department of Microbiology Rajshahi Medical College Rajshahi-6000. Bangladesh 